\title{
The Insulin Receptor Tyrosine Kinase Substrate p58/53 and the Insulin Receptor Are Components of CNS Synapses
}

\author{
Mary-Alice Abbott, ${ }^{1,2}$ David G. Wells, ${ }^{1}$ and Justin R. Fallon ${ }^{1}$ \\ 2University of Massachusetts Graduate School of Biomedical Sciences, Worcester, Massachusetts 01655, and \\ 1 Department of Neuroscience, Brown University, Providence, Rhode Island 02912
}

The synapse is the primary locus of cell-cell communication in the nervous system. It is now clear that the synapse incorporates diverse cell signaling modalities in addition to classical neurotransmission. Here we show that two components of the insulin pathway are localized at CNS synapses, where they are components of the postsynaptic density (PSD). An immunochemical screen revealed that polypeptides of 58 and $53 \mathrm{kDa}$ (p58/53) were highly enriched in PSD fractions from rat cerebral cortex, hippocampus, and cerebellum. These polypeptides were purified and microsequenced, revealing that p58/53 is identical to the insulin receptor tyrosine kinase substrate

The synapse is the predominant site of cell-cell communication in the nervous system. In both the central and peripheral nervous systems, synapses are characterized by the precise apposition of the presynaptic nerve terminal and postsynaptic apparatus. Fast synaptic transmission relies on the coordinated localization of synaptic vesicles and neurotransmitter receptors at this site (Salpeter, 1987; Peters et al., 1991). Synapses are also distinguished by the presence of specialized molecular machinery for regulated exocytosis, neurotransmitter receptor clustering, and signal transduction (Hall and Sanes, 1993; Sheng and Wyszynski, 1997; Somogyi et al., 1998). Notably, synapses also support a range of other cell-cell signaling modalities. For example, neurotrophins and growth factors can modulate synaptic growth, plasticity, and function (Lohof et al., 1993; Kang and Schuman, 1995).

Insulin and its receptor are expressed in the brain, where they are likely to regulate glucose homeostasis and gene expression (Wozniak et al., 1993). Moreover, a number of findings have also suggested a relationship between insulin and Alzheimer's disease (Craft et al., 1996; Frolich et al., 1998; Hoyer, 1998; Wickelgren, 1998). For example, insulin action inhibits tau hyperphosphorylation and thus may block the formation of neurofibrillary tangles (Hong and Lee, 1997). In addition, insulin and its receptor may also play a role at synapses (Unger et al., 1989; Wozniak et al., 1993; Schechter et al., 1996). Destruction of insulin receptors by intracerebroventricular injection of streptozotocin leads to longterm deficits in learning and memory (Lannert and Hoyer, 1998).

\footnotetext{
Received April 8, 1999; revised June 7, 1999; accepted June 15, 1999.

This work was supported in part by an $\mathrm{MD} / \mathrm{PhD}$ predoctoral fellowship from the American Heart Association (M.-A.A.), an individual National Research Scientist postdoctoral award (NS10343; D.G.W.), the Muscular Dystrophy Association, and National Institutes of Health Grants HD23924 and MH53571. We acknowledge the generous gifts of reagents from E. Ozawa, R. Roth, and M. Czech. We also thank A. Dosemeci for providing initial PSD fractions.

Correspondence should be addressed to Justin Fallon, Department of Neuroscience, Brown University, Box 1953, 190 Thayer Street, Providence, RI 02912. Copyright (C) 1999 Society for Neuroscience 0270-6474/99/197300-09\$05.00/0
}

p58/53 (IRSp53). Our analysis of IRSp58/53 mRNA suggests that within rat brain there is one coding region for IRSp58 and IRSp53; we find no evidence of alternative splicing. We demonstrate that IRSp58/53 is expressed in the synapse-rich molecular layer of the cerebellum and is highly concentrated at the synapses of cultured hippocampal neurons, where it colocalizes with the insulin receptor. Together, these data suggest that insulin signaling may play a role at CNS synapses.

Key words: insulin receptor; postsynaptic density; insulin receptor substrate; hippocampal neurons; brain; IRSp53
Insulin can be released from both cultured neuronal cells and synaptosomes in an activity-dependent fashion (Clarke et al., 1986; Wei et al., 1990). Moreover, insulin can recruit $\mathrm{GABA}_{\mathrm{A}}$ receptors to postsynaptic domains (Wan et al., 1997), suggesting a role for this hormone in synaptic plasticity.

The insulin receptor is a tyrosine kinase, but many of its actions require accessory molecules known as insulin receptor substrates (e.g., IRS-1, IRS-2, and IRS-3) (White and Yenush, 1998). In peripheral tissues, these substrates become phosphorylated by the insulin receptor and then coordinate flexible and diverse signaling pathways (Shepherd et al., 1998). In addition, IRS proteins exhibit distinct subcellular localizations, raising the possibility that they subserve spatially and qualitatively distinct intracellular signaling events (Anai et al., 1998). Therefore, characterizing insulin receptor substrates and determining their localization in the CNS may provide insights into diverse insulin actions in the brain.

In the CNS, many synaptic signaling molecules are concentrated in the postsynaptic density (PSD) (for review, see Sheng, 1997; Ziff, 1997). In the current study, we show that the insulin receptor substrate IRSp58/53 is highly enriched in PSD fractions. Microsequencing of IRSp58 and IRSp53 polypeptides suggests they differ only in some post-translational modification. A survey of several tissues revealed that IRSp58/53 and its mRNA are most highly expressed in the brain. IRSp58/53 is localized in the dendritic layers of the cerebellum and is concentrated at synapses in cultured hippocampal neurons. Finally, we show that the insulin receptor is both concentrated at synapses and is a component of the PSD fraction. Together, these data suggest that the synapse is an important site of specialized insulin signaling in the brain.

\section{MATERIALS AND METHODS}

Brain subcellular fractions. PSD fractions were prepared according to the method described elsewhere (Carlin et al., 1980; Dosemeci and Reese, 1993; Wu et al., 1998). The absence of presynaptic contaminants and enrichment of PSD proteins in this fraction was confirmed by Western 
blotting with antibodies to NMDA receptor subunit $1, \alpha-\mathrm{Ca}^{2+}$ / calmodulin-dependent kinase II ( $\alpha$-CaMKII), and synaptophysin (Wu et al., 1998).

Antibodies. Ab98 antiserum was raised by immunizing a rabbit with the peptide KAPLPPPEYPSQ (a sequence in the cytosolic domain of $\beta$-dystroglycan that was used for the production of antibody PA3a; Yoshida et al., 1993) and was affinity-purified (Quality Controlled Biochemicals, Hopkinton, MA). The anti-IRSp58/53 polyclonal antibody was raised by injecting a rabbit with the MAP-conjugated peptide DKDDLALPPPDYGT (Research Genetics, Inc., Huntsville, AL) and was affinity-purified. Immunoabsorption was performed by mixing the primary antibody with its corresponding peptide for $2 \mathrm{hr}$ to overnight at $4^{\circ} \mathrm{C}$. The IRSp53 monoclonal antibody H720 is described elsewhere (Yeh et al., 1996).

Insulin receptor $\beta$-subunit polyclonal antibody (C-19) was obtained from Santa Cruz Biotechnology (Santa Cruz, CA). An anti-peptide antiserum to $\beta$-dystroglycan (12031C) was a generous gift of L. Kunkel (Howard Hughes Medical Institute, Harvard Medical School). Monoclonal anti- $\beta$-dystroglycan antibody NCL-43DAG was obtained from Vector Laboratories (Burlingame, CA). Monoclonal antibodies to synaptophysin (SY38) and to $\alpha$-CaMKII (6G9) were obtained from Boehringer Mannheim (Irvine, CA). Antibody to NMDA receptor subunit NR1 (54.1) was obtained from PharMingen (San Diego, CA).

Western blotting. Protein concentrations were determined with the BCA protein assay (Pierce, Rockford, IL) using BSA as a standard. Equal quantities of homogenate, synaptosomal, and PSD fraction proteins were separated on 10 or $5-15 \%$ gradient gels by SDS-PAGE, transferred onto nitrocellulose membranes, and incubated with primary antibodies followed by alkaline phosphatase-conjugated goat anti-rabbit or anti-mouse IgG (Boehringer Mannheim, Indianapolis, IN). Bound antibody was visualized using the 5-bromo-4-chloro-3-indolyl phosphate/ nitro blue tetrazolium substrate system (Promega, Madison, WI). In some experiments, lysates of Chinese hamster ovary (CHO).T cells, which overexpress insulin receptors (generously provided by M. Czech, University of Massachusetts Medical Center; Baltensperger et al., 1996), were also analyzed.

Hydrophobic interaction chromatography. For hydrophobic interaction chromatography (HIC), PSDs were solubilized overnight at $4^{\circ} \mathrm{C}$ in $8 \mathrm{M}$ urea, $1 \mathrm{M} \mathrm{NaCl}, 5 \mathrm{~mm}$ dithiothreitol (DTT), $50 \mathrm{~mm}$ sodium phosphate buffer, $\mathrm{pH}$ 7.5. The soluble fraction was then made $4 \mathrm{M}$ in urea and incubated with HIC matrix (high-performance phenyl-Sepharose; Pharmacia Biotech, Piscataway, NJ) for $3 \mathrm{hr}$ at $4^{\circ} \mathrm{C}$. The $\mathrm{HIC}$ matrix was then washed, preeluted in the same buffer with $0.8 \mathrm{M} \mathrm{NaCl}$, and eluted with the same buffer in $0.1 \mathrm{M} \mathrm{NaCl}$. Apomyoglobin (Sigma, St. Louis, MO) was added as a carrier to the eluate, and the proteins were precipitated with trichloroacetic acid.

Two-dimensional gel electrophoresis. Isoelectric focusing (IEF) strips (Immobiline Dry Strips, pH 3-10, $11 \mathrm{~cm}$; Pharmacia) were rehydrated for $6 \mathrm{hr}$ to overnight at room temperature in two-dimensional (2D) samplerehydration buffer [8 M urea, 2\% 3-[(3-cholamidopropyl)dimethylammonio]-1-propanesulfonic acid, 2\% immobilized $\mathrm{pH}$ gradient buffer 3-10L (Pharmacia), and 0.3\% DTT. Samples were loaded at the anodic end of the IEF strip, and IEF was performed at $20^{\circ} \mathrm{C}$ on a Multiphor II apparatus (Pharmacia) for $1 \mathrm{hr}$ at $300 \mathrm{~V}$ and $15 \mathrm{hr}$ at $1400 \mathrm{~V}$. The strips were then equilibrated and electrophoresed in the second dimension (10\% gel, SDS-PAGE), as per the manufacturer's instructions. The 2D gels were stained with either silver (Morrissey, 1981) or Coomassie blue or transferred $(10 \mathrm{~V}, 16 \mathrm{hr})$ to nitrocellulose for Western blotting.

Matrix-assisted laser desorption ionization time-of-flight mass spectrometry and peptide sequencing. HIC eluates separated by 2D electrophoresis were visualized by Coomassie blue stain, and the bands corresponding to p58 and p53 were excised from the gel. The polypeptides were recovered from the gel and subjected to trypsin digestion. Peptide masses were determined by matrix-assisted laser desorption ionization time-of-flight mass spectrometry (MALDI-TOF MS). MS-Fit search software was then used to compare the p58 and p53 mass profiles to known proteins. Tryptic fragments from p58 and p53 were separated by HPLC, and peptide sequence was obtained from three fragments of p58 (J. Leszyk, Worcester Foundation Protein Sequencing Facility, Worcester, MA).

In vitro phosphorylation of PSD fraction proteins. The method used is a modification of a procedure described elsewhere (Dosemeci et al., 1994). PSDs were pretreated on ice for $3 \mathrm{hr}$ with occasional mixing in 20 mM HEPES, pH 7.4, and $100 \mathrm{~mm}$ DTT. PSDs were diluted to a final concentration of $0.4 \mathrm{mg}$ of protein $/ \mathrm{ml}$ in phosphorylation solution $(5 \mathrm{~mm}$ $\mathrm{MgCl}_{2}, 50 \mu \mathrm{g} / \mathrm{ml}$ leupeptin, $20 \mathrm{~mm}$ DTT, $20 \mathrm{~mm}$ HEPES, pH 7.4, $1 \mathrm{~mm}$
$\mathrm{CaCl}_{2}$, and $1 \mathrm{~mm}$ orthovanadate, with or without $100 \mu \mathrm{M} \mathrm{ATP}$ ), and incubated at $37^{\circ} \mathrm{C}$ for $5 \mathrm{~min}$. The reaction was quenched by the addition of SDS sample buffer.

Northern blot hybridization. A ${ }^{32} \mathrm{P}$-labeled probe was synthesized by PCR using the IRSp53 cDNA clone (provided by R. Roth, Stanford University School of Medicine; described by Yeh et al., 1996) as template, and the primer pair F1, AAGAGCGTGACCCCGAAGAACAGC; and R1, AACCAGCCCCGCATTTTG.

The rat Multiple Tissue Northern Blot (Clontech, Palo Alto, CA) was probed as instructed by the manufacturer. The most stringent wash performed was $0.1 \times \mathrm{SSC}$ and $0.1 \% \mathrm{SDS}$ at $65^{\circ} \mathrm{C}$ for $40 \mathrm{~min}$.

$R N A$ isolation and RT-PCR. RNA was isolated from $20 \mathrm{mg}$ of rat cerebral cortex by the RNeasy mini kit (Qiagen, Chatsworth, CA). The total RNA $(30 \mu \mathrm{g})$ was reverse-transcribed using random primers, and this reaction product was used as the template for PCR. The PCR conditions were $3 \mathrm{~min}$ at $94^{\circ} \mathrm{C}, 40$ cycles $\left(30 \mathrm{sec}\right.$ at $94^{\circ} \mathrm{C}, 1 \mathrm{~min}$ at $55^{\circ} \mathrm{C}$, and $4 \mathrm{~min}$ at $68^{\circ} \mathrm{C}$ ), and $8 \mathrm{~min}$ at $68^{\circ} \mathrm{C}$. The sequences of the primers used are as follows, $5^{\prime}$ to $3^{\prime}$ : A, GTGTAGCCGGGACCCAGGACCAT; B, CGAGGAGCGGAGGAGGTTCTGC; C, AAGAGCGTGACCCCGAAGAACAGC; D, AACCAGCCCCGCATTTTG; E, ACGGCCACACTGTAGGGTCTCTGC; and F, TCTAGTCAGGGGCAGCTCAAAATC.

Tissue sections and immunohistochemistry. Brains from adult rats were immersed in freezing isopentane, mounted in OCT embedding medium, and equilibrated to $-20^{\circ} \mathrm{C}$. Frozen sections $(8 \mu \mathrm{m})$ were cut, air-dried onto glass slides, fixed in $\mathrm{MeOH}$ at $-20^{\circ} \mathrm{C}$ for $10 \mathrm{~min}$, and rehydrated in PBS with $0.1 \%$ Triton X-100 (PBST). The sections were blocked for $1 \mathrm{hr}$ at room temperature with PBST, $1 \%$ BSA, $10 \%$ horse serum, and $1 \%$ goat serum. The primary antibodies anti-IRSp58/53 (with or without peptide) and rabbit anti-synapsin-I (1:3000; provided by Pietro DeCamilli, Howard Hughes Medical Institute, Yale University School of Medicine; Malgaroli et al., 1989) were diluted in block and were applied overnight at $4^{\circ} \mathrm{C}$. The slides were washed at room temperature for $2 \mathrm{hr}$ in PBST with stirring and one wash solution change. Cy3-conjugated goat anti-rabbit IgG (1:500-1:4000; Jackson ImmunoResearch, WestGrove, PA) or FITC-conjugated goat anti-mouse IgG, rat-absorbed (1:100; Vector Laboratories, Burlingame, CA) was applied for $3 \mathrm{hr}$ at room temperature. The sections were washed as above, dehydrated in $-20^{\circ} \mathrm{C}$ $\mathrm{MeOH}$ for $10 \mathrm{~min}$, allowed to air dry, and mounted in Citifluor (Ted Pella, Redding, CA). Immunostaining was visualized by indirect immunofluorescence using a Nikon E800 microscope. Images were captured with a Photometrics CCD camera using IP Lab systems software.

Hippocampal neuron cultures and immunohistochemistry. Low-density cultures were created as previously described (Goslin and Banker, 1991; Wu et al., 1998). After 19-21 d, the cells were fixed with $4 \%$ paraformaldehyde at $37^{\circ} \mathrm{C}$ for $20 \mathrm{~min}$, covered with saponin $(0.05 \%)$ for $5 \mathrm{~min}$. and then incubated in blocking solution (MEM, 10\% horse serum, 1\% goat serum, and $1 \%$ BSA). The primary antibodies, mouse antisynaptophysin (1:20; Boehringer Mannheim), rabbit anti-IRSp58/53 (1: $5)$, and mouse insulin receptor $\beta$-subunit (1:40, C-19; Santa Cruz Biotechnology) were applied overnight at $4^{\circ} \mathrm{C}$. Species-specific secondary antibodies, directly conjugated to either FITC or $\mathrm{Cy} 3$, were applied for $1 \mathrm{hr}$ at room temperature. Coverslips were mounted onto glass slides with Citifluor.

\section{RESULTS}

\section{Polypeptides p58 and p53 are enriched in the postsynaptic density fraction}

We were initially interested in determining the distribution of a known protein ( $\beta$-dystroglycan) in the rat brain. We performed Western blot analysis on homogenate, synaptosomes, and PSDenriched fractions. Antiserum Ab98 recognized a polypeptide of $\sim 43 \mathrm{kDa}$ in brain homogenate and synaptosome fractions (Fig. $1 A)$. This polypeptide co-migrated with $\beta$-dystroglycan from muscle and was also bound by the anti- $\beta$-dystroglycan antibodies NCL-43DAG and 12031-C (data not shown). Thus we identified this $43 \mathrm{kDa}$ polypeptide as $\beta$-dystroglycan.

Ab98 also recognized a pair of polypeptides, termed p58 and p53, in the PSD fraction (Fig. 1). p58 and p53 were highly enriched in the PSD fraction, because they were not detected in 
A.

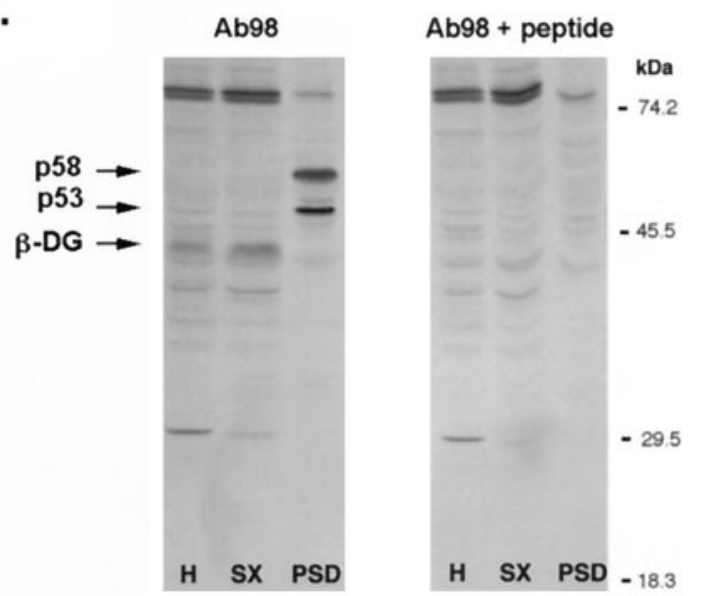

B.



C.

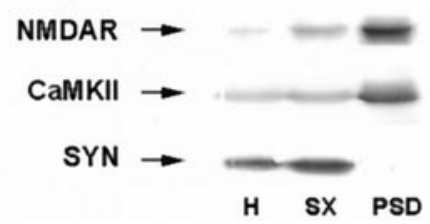

Figure 1. Polypeptides of $58 \mathrm{kDa}$ and $53 \mathrm{kDa}$ are enriched in the PSD fraction. $A$, Homogenate, synaptosome, and PSD fractions from rat brain were separated by SDS-PAGE, transferred to nitrocellulose, and probed with Ab98 (left) or Ab98 that had been preabsorbed with peptide (right). $\beta$-Dystroglycan is observed in the homogenate and synaptosomal fractions $(\beta-D G)$. A pair of polypeptides of 58 and $53 \mathrm{kDa}$ is specifically detected in the PSD fraction ( $p 58, p 53)$. Binding of Ab98 to all three polypeptides is eliminated when the antibody was preabsorbed $(A b 98+$ peptide). Mobilities of molecular weight standards are indicated. $\mathrm{H}, \mathrm{Ho}-$ mogenate; $S X$, synaptosomes; $P S D$, postsynaptic density fraction. $B$, Western blots of homogenate, synaptosomes, and PSD fractions from the indicated brain regions were probed with antibody Ab98. p58 and p53 are selectively enriched in the PSD fractions from all areas examined. $C$, Western blot of homogenate, synaptosome, and PSD fractions from cerebral cortex probed with antibodies to NMDA receptor subunit NR1, $\alpha$-CaMKII, and synaptophysin.

blots of homogenate or synaptosomes that contained the same amount of total protein (Fig. $1 A$ ). p58 and p53 were enriched in PSD fractions isolated from rat cerebral cortex, cerebellum, and hippocampus (Fig. $1 B$ ). The selective enrichment of p58 and p53 closely parallels that of known PSD constituents such as $\alpha$-CaMKII and the NMDA receptor subunit NR1 (Fig. $1 C$ ). In contrast, $\beta$-dystroglycan (migrating at $43 \mathrm{kDa}$ ) was present in brain homogenate and was modestly enriched in synaptosomes, but was not detected in PSD fractions from cerebral cortex (Fig. $1 A$ ) or other brain regions (data not shown). Antibodies NCL43DAG and 12031-C revealed a similar distribution of $\beta$-dystroglycan in these fractions. However, neither of these reagents bound either p58 or p53 (data not shown).

\section{Purification of p58 and p53}

We purified p58 and p53 to determine whether they were related to $\beta$-dystroglycan or were unrelated yet immunologically crossreactive. Protein staining of one-dimensional SDS gels showed that p58 and p53 are minor components of the PSD fraction; moreover, they were not well resolved from other, more abundant polypeptides (data not shown). To achieve improved separation of p58 and p53 and to further investigate their biochemical properties, we separated the PSD fraction proteins by charge and size using 2D gel electrophoresis (Fig. 2A). This method yielded substantial improvement in the isolation of p58 and p53: unlike the majority of the PSD proteins, the doublet migrated to a basic isoelectric point ( $\mathrm{pI}, \sim 9)$ free from the bulk of PSD proteins. The p58 and p53 bands migrated as a series of closely spaced spots of differing isoelectric points, suggesting that these polypeptides may be post-translationally modified (see below).

p58 and p53 were virtually insoluble in all nonionic detergents tested. Furthermore, they were not extracted in $3 \% \mathrm{~N}$-lauroyl sarcosinate (data not shown). Such solubility properties indicate that these polypeptides are tightly associated with the "core" PSD (Kennedy, 1997). However, p58 and p53 could be efficiently solubilized in $8 \mathrm{M}$ urea. Thus, we fractionated the urea-solubilized PSD proteins by HIC. p58 and p53 bound to the HIC matrix, whereas the majority of the PSD proteins did not. Elution of the HIC column thus yielded a fraction that was highly enriched in p58 and p53. We then used 2D electrophoresis to achieve the final purification of p58 and p53 (Fig. 2B).

\section{Mass spectrometry analysis and peptide microsequencing of p58 and p53}

To identify p58 and p53, we used MALDI-TOF mass spectrometry to obtain mass profiles of the gel-purified polypeptides. Comparison of these profiles with computer-generated mass profiles of protein sequences in the National Center for Biotechnical Information database showed that rat p58 and p53 were highly homologous to hamster IRSp58/53 (Table 1, Fig. 3). This pair of polypeptides was first identified in $\mathrm{CHO}$ cells, and the cDNA encoding IRSp53 was subsequently cloned (Yeh et al., 1996). However, the precise relationship between IRSp58 and IRSp53 was not established in that study.

Sixty-five percent of both the p58 masses (15 of 23) and the p53 masses (13 of 20) we obtained by mass spectrometry matched the tryptic digest masses computed from the deduced IRSp53 amino acid sequence (data not shown). There were eight p58 masses that did not correspond to a computed IRSp53 mass, but six of these masses were shared by p53. Two p58 masses and one p53 mass were unique. Only slight differences were observed when the HPLC chromatograms of the p58 and p53 tryptic digests were compared (data not shown). Together, these data indicate that the primary structures of p58 and p53 are very similar to the polypeptide encoded by IRSp53 and to each other.

To verify the identification of p58 and p53 as IRSp53, we obtained amino acid sequence from three of the p58 tryptic fragments. Of the 33 amino acids obtained, all perfectly matched the published sequence of the IRSp53 cDNA (Table 1, Fig. 3; data not shown). The predicted pI of IRSp53 is 8.8, which corresponds well to the basic pI we determined for p58 and p53. Western blots of PSD fractions probed with monoclonal antibody H720 further confirmed the identification of p58 and p53 as IRSp58/53 (data not shown). We will hereafter refer to p58 and p53 as IRSp58/53. 
A. PSD fraction



B. HIC eluate

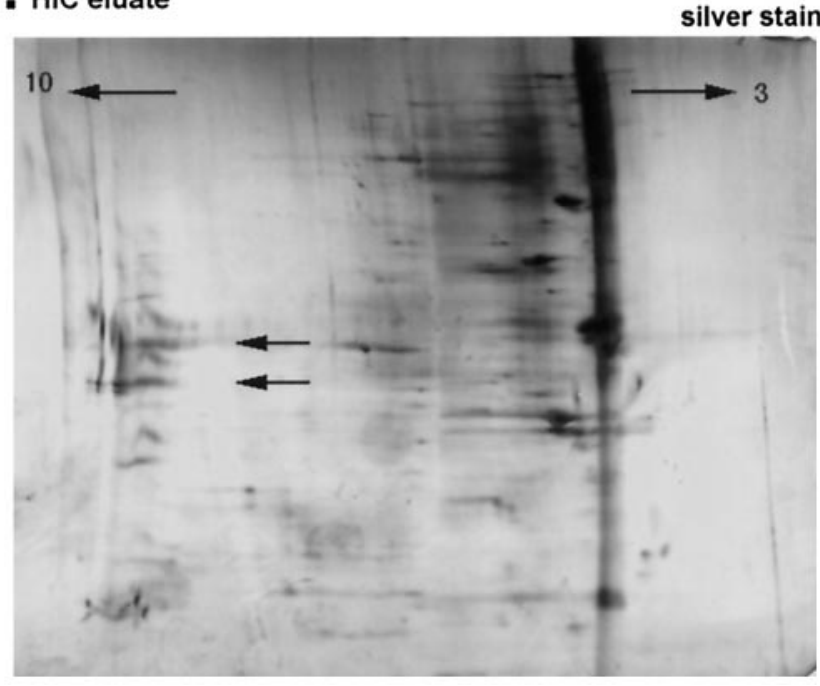

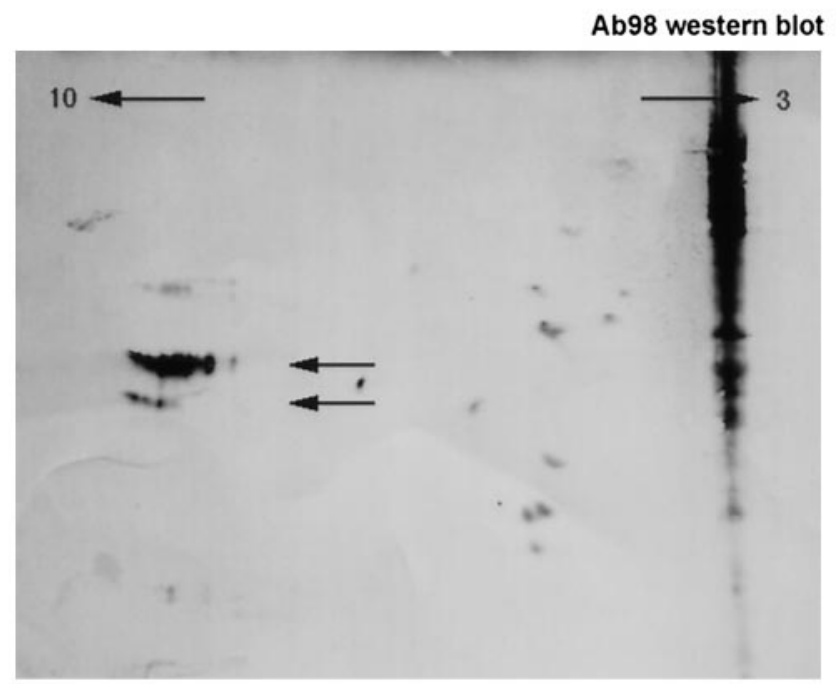

Ab98 western blot

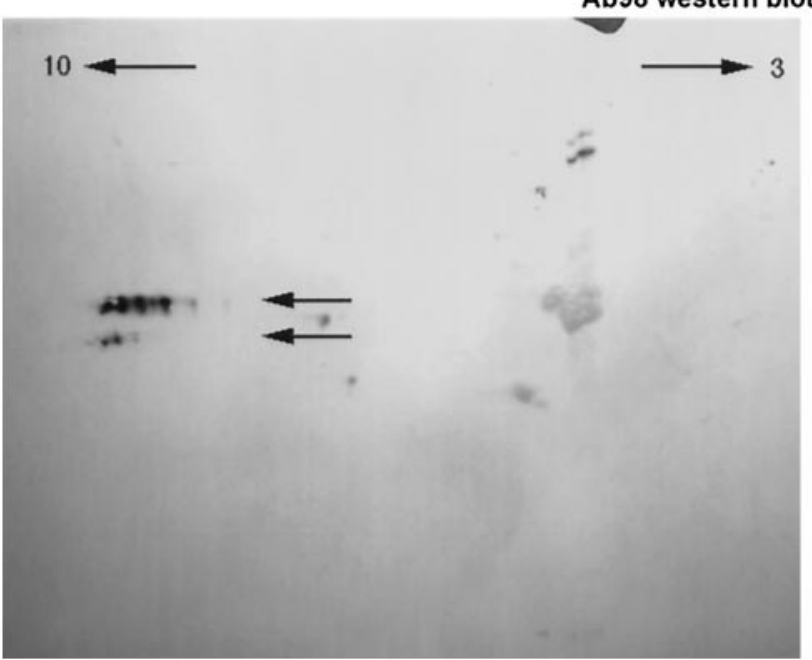

Figure 2. Purification of $\mathrm{p} 58$ and $\mathrm{p} 53$ by $2 \mathrm{D}$ gel electrophoresis and hydrophobic interaction chromatography. $A$, Two-dimensional gel electrophoresis was used to separate PSD fraction proteins. Gels of equivalent samples were silver-stained (left) or blotted to nitrocellulose and probed with Ab98 (right). The positions of $\mathrm{p} 58$ and p53, as visualized by Western blotting, are indicated by the pair of arrows. The migration of p58 and p53 in the first dimension indicates that these polypeptides are basic (pI, 9). Comparison of silver stain and Western blot shows that p58 and p53 are minor components of the PSD fraction. $B$, The PSD fraction proteins were solubilized in urea, loaded onto a HIC column in $1 \mathrm{~m} \mathrm{NaCl}$ buffer, and then eluted in $0.1 \mathrm{M}$ NaCl salt buffer. 2D gels of the HIC eluates were either silver-stained (left) or blotted to nitrocellulose and probed with Ab98 (right). p58 and p53 are readily visualized in silver-stained gels of HIC eluate (arrows), indicating that they are highly enriched by this procedure.

\section{Relationship of IRSp58 and IRSp53}

In the course of our biochemical studies of IRSp58/53, we consistently encountered an $\sim 5 \mathrm{kDa}$ difference between the molecular weights of IRSp58 and IRSp53. However, neither mass spectrometry nor HPLC analysis yielded any indication that the primary structure of these polypeptides differed. Western analysis revealed that IRSp58/53 was identical in rat and mouse (data not shown). However, in the porcine PSD fraction the IRSp58 species was prominent, and the IRSp53 species was barely detectable (Fig. 4). In vitro phosphorylation of rat PSD proteins resulted in an upward shift in the mobility of both polypeptides, suggesting that they are substrates of a kinase(s) in the PSD fraction. However, this shift could not account for the $5 \mathrm{kDa}$ difference between
IRSp58 and IRSp53 (Fig. 4). Similarly, enzymatic deglycosylation did not yield any consolidation of the doublet (data not shown). Thus, we could find no evidence that these post-translational modifications are the basis for the difference in the apparent molecular weights of IRSp58 and IRSp53.

\section{Distribution of IRSp58/53 mRNA}

We next examined the distribution and configuration of the IRSp58/53 transcript. We probed Northern blots to determine the tissue distribution of IRSp58/53 mRNA. Transcripts of 2.4 and $3.5 \mathrm{~kb}$ were detected (Fig. 5). Brain contained the highest level of IRSp58/53 mRNA, with the $3.5 \mathrm{~kb}$ transcript predominating. Varying amounts of these transcripts were observed in other tissues. Neither transcript was detected in skeletal muscle. 
Table 1. Mass spectrometry and peptide microsequence analysis of PSD58/53

\begin{tabular}{|c|c|c|c|c|}
\hline \multicolumn{2}{|c|}{ p58 and p53 tryptic fragments } & \multicolumn{2}{|c|}{ Predicted IRSp53 tryptic fragments ${ }^{a}$} & \multirow[b]{2}{*}{ Peptide microsequence $^{d}$} \\
\hline p58 masses & p53 masses & IRSp53 masses ${ }^{b}$ & Position $^{c}$ & \\
\hline 912.7 & & 913.1 & $51-58$ & GYFDALVK \\
\hline 1788.2 & 1789.7 & 1788.0 & $157-171$ & YSDKELQYIDAISNK \\
\hline 1208.1 & 1208.4 & 1208.2 & $412-421$ & DGWHYGESEK \\
\hline
\end{tabular}

${ }^{a}$ The calculated masses of the IRSp53 tryptic fragments that correspond to p58 or p53 masses are listed.

${ }^{b}$ All masses are in daltons.

${ }^{c}$ The amino acid positions of these fragments are based on the numbering system of Yeh et al (1996).

${ }^{d}$ Peptide microsequences obtained from the three p58 tryptic fragments were identical to deduced IRSp53 amino acid sequences.



Figure 3. Structure of IRSp53. IRSp53 is predicted to contain several protein-protein interaction domains: one $\mathrm{SH} 3$ domain, one $\mathrm{SH} 3$ binding domain, and one WW binding domain (Yeh et al., 1998). Additionally, there are 25 potential serine/threonine phosphorylation sites (protein kinase $\mathrm{A}$, protein kinase $\mathrm{C}$, and casein kinase; data not shown) and two potential tyrosine phosphorylation sites $(p Y)$. The positions of the peptide microsequences obtained from purified p58 are noted. The positions of the epitope that is likely to be recognized by Ab98 and the peptide used to generate the polyclonal anti-IRSp58/53 antiserum are indicated. The region that corresponds to the IRSp53 DNA fragment used as a probe for Northern blots is also shown.

A.

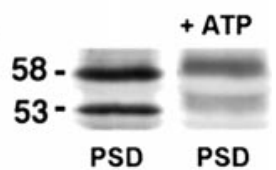

B.

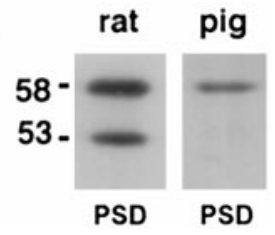

Figure 4. Relationship of IRSp58 and IRSp53 from PSDs. A, PSD fractions from rat brain were incubated under conditions promoting in vitro phosphorylation (see Materials and Methods) in either the absence (left) or presence (right) of exogenous ATP. Western blotting with Ab98 shows that IRSp58 and IRSp53 undergo similar gel shifts after in vitro phosphorylation. $B$, Blots of PSD fractions from rat (left) and pig (right) were probed with antibody Ab98. Comparison of these reveals species differences in the expression of PSD fraction IRSp58 and IRSp53. Although similar amounts of IRSp58 and IRSp53 are detected in rat PSDs, only IRSp58 is detected in pig PSDs.

\section{Organization of IRSp58/53 mRNA}

We next considered the possibility that the multiple transcripts observed in the Northern blots could correspond to alternatively spliced mRNAs. We searched the Expressed Sequence Tag (EST) database using the BLAST algorithm (Altschul et al., 1990) for sequences that might represent IRSp53 homologs. We identified a large set of IRSp53-homologous ESTs that spanned the entire open reading frame of IRSp53 (data not shown).
A.

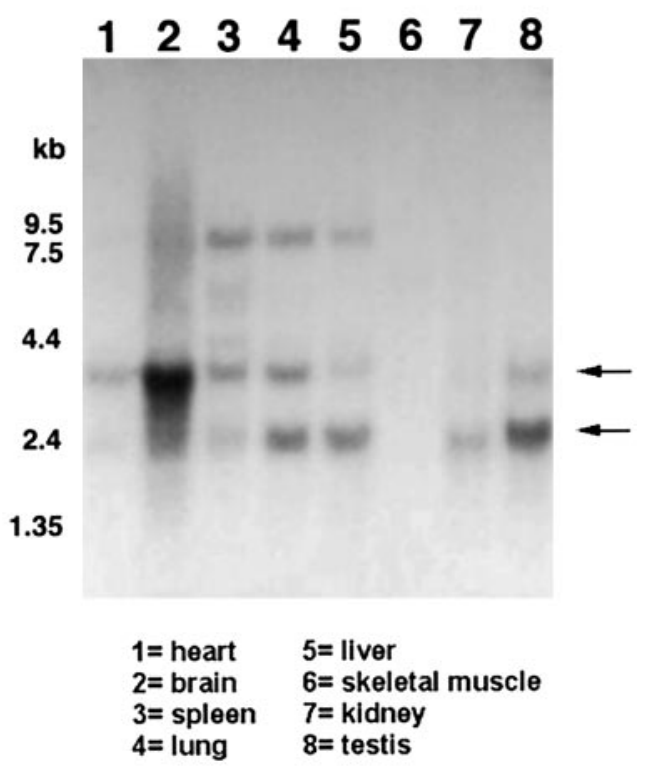

B.

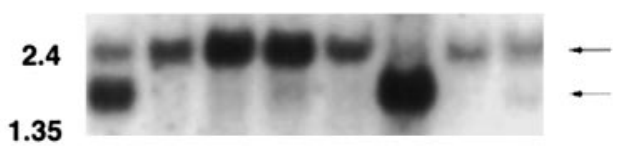

Figure 5. Tissue distribution of IRSp58/53 mRNAs. $A$, A multiple rat tissue Northern blot was probed with a radiolabeled IRSp58/53 oligonucleotide probe (248 bp; see Fig. 3 ) as described in Materials and Methods. Transcripts of $2.4,3.5$, and $8 \mathrm{~kb}$ are observed. The highest level of IRSp58/53 mRNA is detected in brain, with the $3.5 \mathrm{~kb}$ transcript predominating. $B$, The blot was rehybridized with a probe for $\beta$-actin to verify the integrity and quantity of the RNA from each tissue.

However, this analysis revealed no divergences from the reported IRSp53 cDNA sequence and thus provided no evidence for alternatively spliced transcripts.

As a further test for variations in the coding sequence of the IRSp58/53 mRNAs, we performed RT-PCR. We isolated total RNA from rat cerebral cortex and reverse-transcribed it using random primers. We then used an array of specific primers that spanned the IRSp53 coding region for PCR analysis. Each of the RT-PCR products generated corresponded in size to a product obtained using IRSp53 cDNA as template; no major additional products were detected (data not shown). Together, these PCR products covered the entire coding region of IRSp53. Thus, in rat brain we find no evidence of alternative splicing within the coding region of IRSp53, suggesting that both IRSp58 and IRSp53 are products of a highly similar or identical mRNA. 


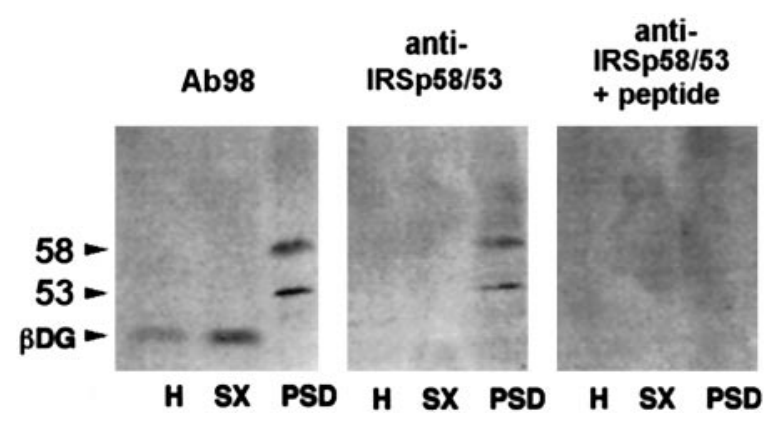

Figure 6. Characterization of the anti-IRSp58/53 antibody. Rabbits were immunized with a 13 amino acid peptide from the predicted amino acid sequence of IRSp58/53, and the resulting antiserum was affinity-purified. On Western blots, anti-IRSp58/53 antibody recognizes polypeptides of 58 and $53 \mathrm{kDa}$, which are also bound by Ab98. However, anti-IRSp58/53 does not recognize $\beta$-dystroglycan. All anti-IRSp58/53 immunoreactivity is abolished if the antibody is preabsorbed with peptide. $H$, Homogenate; $S X$, synaptosomes; $P S D$, postsynaptic density fraction.

\section{Localization of IRSp58/53 to synapses}

To determine whether IRSp58/53 is expressed at intact synapses, we raised and affinity purified a specific anti-IRSp58/53 antiserum. The specificity of this reagent for IRSp58/53 was verified by Western blotting and immunoabsorption (Fig. 6). In contrast to $\mathrm{Ab} 98$, this antiserum did not recognize $\beta$-dystroglycan.

To determine the distribution of IRSp58/53 in intact brain, we performed immunohistochemistry on frozen sections. The cytoarchitecture of the cerebellum consists of granular and pyramidal cell soma layers and a synapse-rich molecular layer. Staining with the anti-IRSp58/53 antibody demonstrated that IRSp58/53 immunoreactivity is prominent in the synapse-rich molecular layer as well as in the granule cell layer of this tissue (Fig. 7A). The specificity of the IRSp58/53 antibody staining was demonstrated by peptide immunoabsorption.

To assess the distribution of IRSp58/53 in further detail, we exploited a system in which individual synapses can be resolved. Primary hippocampal neurons in low density cultures have well differentiated axons and dendrites and numerous synapses. These synapses can be reliably visualized using antibodies to synaptophysin (Fletcher et al., 1991). Double labeling with antisynaptophysin and anti-IRSp58/53 showed that IRSp58/53 immunoreactivity was localized at the majority of synapses on these cells (Fig. 7B). Little nonsynaptic localization was observed. Together, these studies indicated that IRSp58/53 is a component of CNS synapses.

\section{Localization of insulin receptors at synapses}

IRSp58/53 has been shown to be an insulin receptor substrate in cultured fibroblasts. Furthermore, IRSp58/53 isolated from brain can be tyrosine-phosphorylated in vitro by the insulin receptor (Yeh et al., 1996). To determine whether the insulin receptor is localized at synapses, we immunostained cultured hippocampal neurons with an antibody directed against the insulin receptor $\beta$-subunit and with an anti-synaptophysin antibody. Figure $8, A$ and $B$, shows that insulin receptors are highly concentrated at synapses on these cells. Insulin receptors are also localized at nonsynaptic regions of the dendrite (Fig. 8B).

A.

synapsin-I



anti-IRSp58/53

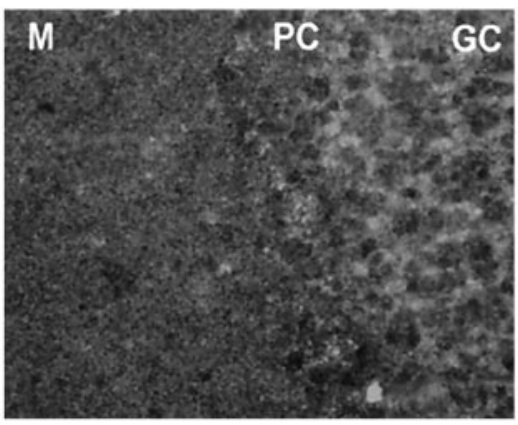

anti-IRSp58/53 + peptide

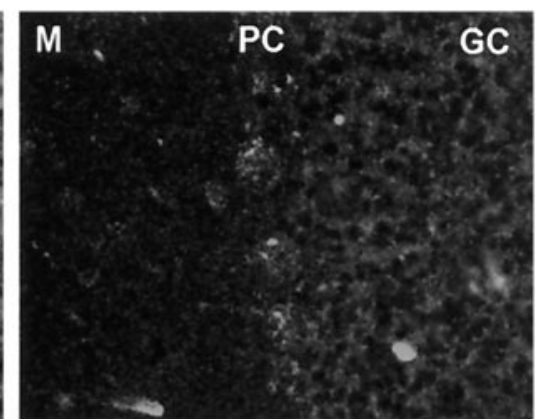

B.

anti-IRSp58/53

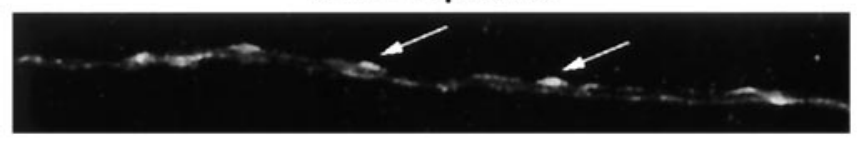

anti-synaptophysin

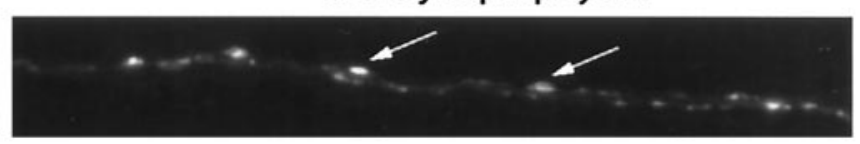

Figure 7. A, Localization of IRSp58/53 in the cerebellar cortex. Sections of rat cerebellum were immunostained with the affinity-purified anti-IRSp58/53 or with anti-synapsin-I antiserum. The synapsin-I immunoreactivity reveals the distribution of synapses. IRSp58/53 immunoreactivity is observed in the synapse-rich molecular layer as well as in the granule cell layer. Anti-IRSp58/53 immunoreactivity is greatly reduced when the antibody was preabsorbed with peptide. Scale bar, $50 \mu \mathrm{m}$. $M$, Molecular layer; $P C$, Purkinje cell layer; $G C$, granule cell layer. $B$, Localization of IRSp58/53 at synapses. Cultured rat hippocampal neurons were immunostained with the affinity-purified anti-IRSp58/53 antiserum (left). IRSp58/53 immunoreactivity is distributed in a punctate pattern along the dendrites of the neurons. The distribution of synapses in the same dendrite was visualized by double labeling with anti-synaptophysin (right). IRSp58/53 immunoreactivity is selectively concentrated at synapses (arrows). 
A.


B.
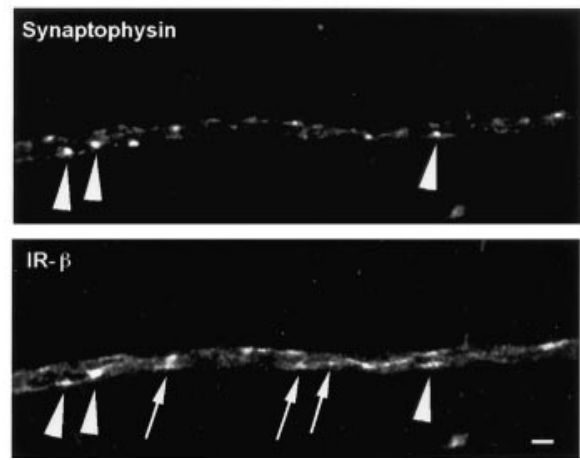

C.

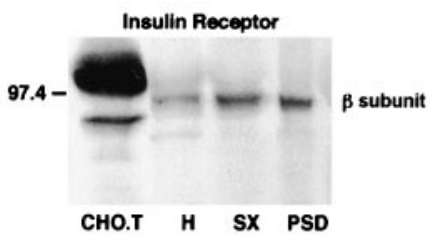

Figure 8. Insulin receptor localization in cultured neurons and brain subcellular fractions. $A$, Cultured rat hippocampal neurons were doubleimmunostained with anti-synaptophysin and anti-insulin receptor $\beta$-subunit antibody $(I R-\beta)$. Insulin receptor immunoreactivity is distributed in a punctate pattern along dendrites. Note that insulin receptor $\beta$-subunit immunoreactivity is concentrated at synapses. Scale bar, $20 \mu \mathrm{M}$. $B$, Highmagnification view of a single dendrite of a cultured hippocampal neuron double labeled with antibodies to the insulin receptor $\beta$-subunit and synaptophysin. IR- $\beta$ immunoreactivity is concentrated at both synaptophysin-positive regions (arrowheads) as well as distributed in apparently nonsynaptic regions (arrows). Scale bar, $5 \mu \mathrm{M}$. C, A Western blot of rat brain subcellular fractions (homogenate, synaptosome, and PSD) and lysate from CHO.T cells was probed with an anti-insulin receptor $\beta$-subunit antibody. High levels of $\beta$-subunit are seen in CHO.T cells (a cell line engineered to overexpress insulin receptors). The $\beta$-subunit of the insulin receptor is detected in brain homogenate and is enriched in synaptosome and PSD fractions.

\section{Insulin receptors are a component of PSD fractions}

We next wished to compare the biochemical fractionation profiles of insulin receptor and IRSp58/53 from brain. In agreement with earlier findings, the molecular weight of the insulin receptor $\beta$-subunit in brain is $\sim 5 \mathrm{kDa}$ less than that expressed by peripheral tissues (Heidenreich et al., 1983). Western blotting showed that the insulin receptor $\beta$-subunit was detected in homogenate and was enriched in both synaptosome and PSD fractions (Fig. $8 C$ ). The degree of enrichment of insulin receptor in PSD fractions was not as great as that observed for PSD components such as NMDA receptor subunit NR1, $\alpha$-CaMKII, and IRSp58/53 (Fig. 1). This observation is in agreement with the localization of the insulin receptor to both nonsynaptic and synaptic regions (Fig. $8 B$; see Discussion). Together, these findings show that both the $\beta$-subunit of the insulin receptor tyrosine kinase and its substrate IRSp58/53 are components of the PSD fraction. This co-localization suggests that these molecules are part of an insulin-dependent signaling pathway at the postsynaptic apparatus.

\section{DISCUSSION}

Insulin is likely to have diverse roles in the CNS. In addition to its probable function in glucose metabolism, there is a growing body of evidence that insulin signaling may factor in cell-cell commu- nication and plasticity (for reviewed, see Wickelgren, 1998). The diverse outcomes of insulin signaling may be coordinated through the spatially regulated expression of insulin receptor tyrosine kinase substrates. Here, we show that the insulin receptor substrate IRSp58/53, and insulin receptors themselves, are localized at synapses in the brain and are components of the postsynaptic density. Signaling via IRSp58/53 may define a synapse-specific role for insulin in the brain.

\section{IRSp58/53 and insulin receptor are localized to synapses}

We began our investigation of synaptic insulin signaling proteins at the level of the PSD, an electron-dense conglomeration of proteins that lies just below the postsynaptic membrane at excitatory synapses. We purified a pair of previously unidentified proteins that were selectively concentrated in PSD fractions. MALDI-TOF mass spectrometry, peptide sequencing, twodimensional electrophoresis, and Western blotting demonstrated that these PSD proteins, p58 and p53, are the insulin receptor substrate p58/53 (IRSp58/53). The IRSp58/53 that we purified from rat is very similar to that cloned from hamster (Table 1).

The striking enrichment of IRSp58/53 in PSD fractions suggested that it may be predominantly expressed at excitatory synapses. Indeed, immunocytochemistry showed that IRSp58/53 
is expressed in the synapse-rich layers of the cerebellum. Furthermore, labeling of cultured hippocampal neurons demonstrated that IRSp58/53 is selectively concentrated at synapses. Neither Western blotting nor immunocytochemistry detected IRSp58/53 expression in cultured glial cells (our unpublished observations). Thus, IRSp58/563 is selectively localized at synapses in the CNS.

The synaptic distribution of IRSp58/53 raised the possibility that insulin receptors are also localized at these structures. Previous work has shown that insulin receptors have been detected in both neurons and glia throughout the brain (Wozniak et al., 1993). However, their subcellular localization was not established. Using immunocytochemistry and Western blotting of brain fractions we show that the insulin receptor is localized at synapses. Together, these findings support the proposal that insulin signaling plays a role at synapses.

\section{Structure of IRSp58/53}

We consistently observed that IRSp58/53 migrates as a pair of polypeptides. However, we could find little evidence that IRSp58 and IRSp53 differed in their primary sequences. HPLC chromatograms of tryptic fragments from p58 and p53 were virtually identical. MALDI-TOF analysis of purified p58 and p53 also revealed similar profiles; only two p58 masses and one p53 mass were unique. Although these masses could represent divergent primary sequences, they could also be attributable to posttranslational modification or proteolysis. Indeed, the relative expression of IRSp58 and IRSp53 is cell- and tissue-specific. Transfection of the IRSp53 cDNA into fibroblasts results in expression of only the IRSp53 species (Yeh et al., 1996). Furthermore, we detect only IRSp58 in PSD fractions from porcine brain. Finally, using RT-PCR we detected only a single species of IRSp53 mRNA in the brain, and a survey of the EST database yielded no evidence of multiple mRNA species. However, our comparative analysis of the IRSp53 cDNA and total rat brain cDNA does not exclude the possibility that differences exist $5^{\prime}$ or $3^{\prime}$ to the IRSp53 coding region. Analysis of the IRSp53 cDNA reveals an open reading frame that encodes for a predicted protein of $57.6 \mathrm{kDa}$ (Yeh et al., 1996). Interestingly, downstream of this first ATG codon are at least six subsequent potential start sites. Use of one of these in particular would yield a polypeptide with a predicted molecular weight of $53.6 \mathrm{kDa}$. Therefore, it is possible that use of alternative initiation sites is the basis for the observation of this pair of polypeptides of 58 and $53 \mathrm{kDa}$. Nevertheless, we think our data best fit a scenario whereby IRSp58 and IRSp53 derive from an identical mRNA coding region, and the difference in these polypeptides is the result of a species- and cell backgrounddependent, post-translational process.

Our investigation of IRSp58/53 was an outgrowth of our use of an antiserum directed against $\beta$-dystroglycan (Ab98). However, comparison of the IRSp53 and $\beta$-dystroglycan sequences revealed very limited sequence homology. The immunological crossreactivity that $\mathrm{Ab} 98$ demonstrated for IRSp58/53 is presumably attributable to a proline-rich stretch of amino acids within its amino acid sequence (KPLPVPPELAPF) that is similar to the $\beta$-dystroglycan peptide used to generate Ab98 (KAPLPPPEYPSQ). Notably, another group has reported a PSD fraction protein (not IRSp58/53) that is immunologically related to $\beta$-dystroglycan (Mummery et al., 1996). To date, however, neither the identity of this $164 \mathrm{kDa}$ PSD fraction protein nor its relationship to $\beta$-dystroglycan has been shown. In sum, our data provide no evidence for the expression of $\beta$-dystroglycan or a related molecule in PSD fractions.

\section{Interactions of IRSp58/53}

There is compelling evidence in support of the functional classification of IRSp58/53 as an insulin receptor substrate in cell lines (Yeh et al., 1996). Furthermore, Yeh and colleagues (1996) demonstrated that IRSp58/53 isolated from brain can be tyrosinephosphorylated in vitro by insulin receptors isolated from CHO.T cells. We have found that after in vitro phosphorylation of PSD fractions, IRSp58/53 displayed a gel shift consistent with phosphorylation by an endogenous kinase(s). Moreover, the insulin receptor is localized at synapses and is a component of PSD fractions. Together, these observations suggest that IRSp58/53 acts as a substrate of the insulin receptor tyrosine kinase at synapses. Studies are currently in progress to determine whether insulin stimulation leads to phosphorylation of IRSp58/53 in intact neurons.

The predicted domain structure of IRSp53 indicates many potential sites for protein-protein interactions, including an Src homology region 3 (SH3) domain, an SH3-binding domain, and a proline-rich WW-binding domain (Yeh et al., 1998). An interaction between an IRSp53 homolog and the intracellular domain of Fas ligand (FasL) has been detected using a yeast two-hybrid assay (GenBank accession U70669). However, we have been unable to demonstrate an interaction between IRSp58/53 and FasL biochemically. We also tested whether IRSp58/53 interacts with the WW domain of dystrophin, a PSD-enriched cytoskeletal protein, but we were unable to co-immunoprecipitate IRSp58/53 and in vitro-expressed dystrophin fragments. Finally, we did not detect co-immunoprecipitation of any native PSD fraction proteins with IRSp58/53 (our unpublished observations). Other investigators have similarly been unable to demonstrate binding partners for IRSp58/53 (Yeh et al., 1996).

\section{IRSp58/53 may define a synapse-specific insulin signaling pathway}

In the periphery, the actions of insulin are effected by distinct sets of signal transduction molecules with characteristic cellular and subcellular distributions (Anai et al., 1998). Similar compartmentalization may also occur in the CNS. Key components of the insulin signaling mechanism, such as insulin receptors and IRS-1, are widely expressed in the brain, where they are often colocalized. However, there are several areas of the brain, including regions of the cerebellum, in which insulin receptor but not IRS-1 is detected (Baskin et al., 1994; Folli et al., 1994; Yamada et al., 1997). In the current study we found that insulin receptors, although co-localized with IRSp58/53 at synapses, are also found in nonsynaptic areas of the dendrite. It seems likely that the insulin receptor will associate with other insulin receptor substrates at these sites. These observations indicate that insulin action in the brain is likely to be subserved by distinct sets of downstream signaling elements.

The data presented here suggest that IRSp58/53 may define a novel class of insulin signaling at excitatory synapses in the brain. One expects that the effect of insulin at synapses is distinct from its global, metabolic control. It seems likely that elucidating the role of insulin signaling at synapses will provide important insights into synaptic function and plasticity.

\section{REFERENCES}

Altschul SF, Gish W, Miller W, Myers EW, Lipman DJ (1990) Basic local alignment search tool. J Mol Biol 215:403-410.

Anai M, Ono H, Funaki M, Fukushima Y, Inukai K, Ogihara T, Sakoda H, Onishi Y, Yazaki Y, Kikuchi M, Oka Y, Asano T (1998) Different subcellular distribution and regulation of expression of insulin receptor 
substrate (IRS)-3 from those of IRS-1 and IRS-2. J Biol Chem 273:29686-29692.

Baltensperger K, Karoor V, Paul H, Ruoho A, Czech MP, Malbon CC (1996) The beta-adrenergic receptor is a substrate for the insulin receptor tyrosine kinase. J Biol Chem 271:1061-1064.

Baskin DG, Schwartz MW, Sipols AJ, D'Alessio DA, Goldstein BJ, White MF (1994) Insulin receptor substrate-1 (IRS-1) expression in rat brain. Endocrinology 134:1952-1955.

Carlin RK, Grab DJ, Cohen RS, Siekevitz P (1980) Isolation and characterization of postsynaptic densities from various brain regions: enrichment of different types of postsynaptic densities. J Cell Biol 86:831-845.

Clarke DW, Mudd L, Boyd Jr FT, Fields M, Raizada MK (1986) Insulin is released from rat brain neuronal cells in culture. $\mathrm{J}$ Neurochem 47:831-836.

Craft S, Newcomer J, Kanne S, Dagogo-Jack S, Cryer P, Sheline Y, Luby J, Dagogo-Jack A, Alderson A (1996) Memory improvement following induced hyperinsulinemia in Alzheimer's disease. Neurobiol Aging 17:123-130.

Dosemeci A, Reese TS (1993) Inhibition of endogenous phosphatase in a postsynaptic density fraction allows extensive phosphorylation of the major postsynaptic density protein. J Neurochem 61:550-555.

Dosemeci A, Gollop N, Jaffe H (1994) Identification of a major autophosphorylation site on postsynaptic density-associated $\mathrm{Ca} 2+$ / calmodulin-dependent protein kinase. J Biol Chem 269:31330-31333.

Fletcher TL, Cameron P, De Camilli P, Banker G (1991) The distribution of synapsin I and synaptophysin in hippocampal neurons developing in culture. J Neurosci 11:1617-1626.

Folli F, Bonfanti L, Renard E, Kahn CR, Merighi A (1994) Insulin receptor substrate-1 (IRS-1) distribution in the rat central nervous system. J Neurosci 14:6412-6422.

Frolich L, Blum-Degen D, Bernstein HG, Engelsberger S, Humrich J, Laufer S, Muschner D, Thalheimer A, Turk A, Hoyer S, Zochling R, Boissl KW, Jellinger K, Riederer P (1998) Brain insulin and insulin receptors in aging and sporadic Alzheimer's disease. J Neural Transm 105:423-438.

Goslin K, Banker G (1991) Rat hippocampal neurons in low-density culture. In: Culturing nerve cells, pp 251-281. Cambridge, MA: MIT.

Hall ZW, Sanes JR (1993) Synaptic structure and development: the neuromuscular junction. Neuron [Suppl] 10:99-121.

Heidenreich KA, Zahniser NR, Berhanu P, Brandenburg D, Olefsky JM (1983) Structural differences between insulin receptors in the brain and peripheral target tissues. J Biol Chem 258:8527-8530.

Hong M, Lee VM (1997) Insulin and insulin-like growth factor-1 regulate tau phosphorylation in cultured human neurons. J Biol Chem 272:19547-19553.

Hoyer S (1998) Is sporadic Alzheimer disease the brain type of noninsulin dependent diabetes mellitus? A challenging. J Neural Transm 105:415-422.

Kang H, Schuman EM (1995) Long-lasting neurotrophin-induced enhancement of synaptic transmission in the adult hippocampus. Science 267:1658-1662.

Kennedy MB (1997) The postsynaptic density at glutamatergic synapses. Trends Neurosci 20:264-268.

Lannert H, Hoyer S (1998) Intracerebroventricular administration of streptozotocin causes long-term diminutions in learning and memory abilities and in cerebral energy metabolism in adult rats. Behav Neurosci 112:1199-208.

Lohof AM, Ip NY, Poo M-M (1993) Potentiation of developing neuromuscular synapses by the neurotrophins NT-3 and BDNF. Nature 363:350-352.

Malgaroli A, DeCamilli P, Meldolesi J (1989) Distribution of alpha latrotoxin receptor in the rat brain by quantitative autoradiography: comparison with the nerve terminal protein synapsin I. Neuroscience 32:393-404.

Morrissey JH (1981) Silver stain for proteins in polyacrylamide gels: a modified procedure with enhanced uniform sensitivity. Anal Biochem 117:307-310.
Mummery R, Sessay A, Lai FA, Beesley PW (1996) beta-dystroglycan: subcellular localisation in rat brain and detection of a novel immunologically related, postsynaptic density-enriched protein. J Neurochem 66:2455-2459.

Peters A, Palay SL, Webster HD (1991) The fine structure of the nervous system: neurons and their supporting cells. New York: Oxford UP.

Qiu WQ, Walsh DM, Ye Z, Vekrellis K, Zhang J, Podlisny MB, Rosner MR, Safavi A, Hersh LB, Selkoe DJ (1998) Insulin-degrading enzyme regulates extracellular levels of amyloid beta-protein by degradation. J Biol Chem 273:32730-32738.

Salpeter MM (1987) Vetebrate neuromuscular junctions: general morphology, molecular organization, and functional consequences. In: The vertebrate neuromuscular junction, pp 1-54. New York: Liss.

Schechter R, Beju D, Gaffney T, Schaefer F, Whetsell L (1996) Preproinsulin I and II mRNAs and insulin electron microscopic immunoreaction are present within the rat fetal nervous system. Brain Res 736:16-27.

Sheng M (1997) Excitatory synapses. Glutamate receptors put in their place [news, comment]. Nature 386:221-223.

Sheng M, Wyszynski M (1997) Ion channel targeting in neurons. Bioessays 19:847-853.

Shepherd PR, Withers DJ, Siddle K (1998) Phosphoinositide 3-kinase: the key switch mechanism in insulin signalling. Biochem J 333:471-490.

Somogyi P, Tamas G, Lujan R, Buhl EH (1998) Salient features of synaptic organisation in the cerebral cortex. Brain Res Brain Res Rev 26:113-135.

Unger J, McNeill TH, Moxley RT, White M, Moss A, Livingston JN (1989) Distribution of insulin receptor-like immunoreactivity in the rat forebrain. Neuroscience 31:143-157.

Wan Q, Xiong ZG, Man HY, Ackerley CA, Braunton J, Lu WY, Becker LE, MacDonald JF, Wang YT (1997) Recruitment of functional GABA(A) receptors to postsynaptic domains by insulin. Nature 388:686-690.

Wei LT, Matsumoto H, Rhoads DE (1990) Release of immunoreactive insulin from rat brain synaptosomes under depolarizing conditions. J Neurochem 54:1661-1665.

White MF, Yenush L (1998) The IRS-signaling system: a network of docking proteins that mediate insulin and cytokine action. Curr Top Microbiol Immunol 228:179-208.

Wickelgren I (1998) Tracking insulin to the mind [news]. Science 280:517-519.

Wozniak M, Rydzewski B, Baker SP, Raizada MK (1993) The cellular and physiological actions of insulin in the central nervous system. Neurochem Int 22:1-10.

Wu L, Wells D, Tay J, Mendis D, Abbott MA, Barnitt A, Quinlan E, Heynen A, Fallon JR, Richter JD (1998) CPEB-mediated cytoplasmic polyadenylation and the regulation of experience-dependent translation of alpha-CaMKII mRNA at synapses. Neuron 21:1129-1139.

Yamada M, Ohnishi H, Sano S, Nakatani A, Ikeuchi T, Hatanaka H (1997) Insulin receptor substrate (IRS)-1 and IRS-2 are tyrosinephosphorylated and associated with phosphatidylinositol 3-kinase in response to brain-derived neurotrophic factor in cultured cerebral cortical neurons. J Biol Chem 272:30334-30339.

Yeh TC, Ogawa W, Danielsen AG, Roth RA (1996) Characterization and cloning of a $58 / 53-\mathrm{kDa}$ substrate of the insulin receptor tyrosine kinase. J Biol Chem 271:2921-2928.

Yeh TC, Li W, Keller GA, Roth RA (1998) Disruption of a putative $\mathrm{SH} 3$ domain and the proline-rich motifs in the 53-kDa substrate of the insulin receptor kinase does not alter its subcellular localization or ability to serve as a substrate. J Cell Biochem 68:139-150.

Yoshida M, Mizuno Y, Nonaka I, Ozawa E (1993) A dystrophinassociated glycoprotein, A3a (one of 43DAG doublets), is retained in Duchenne muscular dystrophy muscle. J Biochem (Tokyo) 114:634-639.

Ziff EB (1997) Enlightening the postsynaptic density. Neuron 19:11631174. 